\author{
ІННОВАЦІЙНІ ЗВУКОВІ ТЕХНОЛОГІЇ \\ ПРОСТОРОВОЇ ЗВУКОПЕРЕДАЧІ: \\ РЕТРОСПЕКТИВА ЗВУКОВИХ \\ ІНСТАЛЯЦІЙ \\ Волкомор Віталій Вікторович \\ Викладач, \\ ORCID: 0000-0003-2401-3079, \\ e-mail:wolkomor2@gmail.com, \\ Київський національний університет \\ культури і мистецтв, \\ вул. Свгена Коновальия, 36, Київ, Украӥна, 01133
}

\begin{abstract}
Мета статті - визначити особливості розвитку мистецтва звукової інсталяції в контексті концепцій акустичного простору другої половини XX - початку XXI ст. Методи дослідження. Застосовано міждисциплінарну методологію критичного просторового аналізу та критичних досліджень в музиці для вивчення концепцій простору й місця, що стали основою для практики звукової інсталяції в середині XX - на початку XXI ст.; системний та еволюційний методи, що посприяли розгляду музичної інсталяції в загальній філософсько-онтологічній площині з метою отримання результатів, корисних у музичних та суміжних науках. Наукова новизна. Досліджено особливості формування й розвитку мистецтва звукової інсталяції крізь призму концепцій акустичного простору другої половини XX - початку XXI ст.; вперше у вітчизняному мистецтвознавстві сутнісні основи звукової інсталяції виявляються в контексті трактування концепції відображеного звукового об’єкту, альтернативних та розширених концепцій простору, зокрема концепції простору як суспільного виробництва; розглянуто поняття «просторовий звук», «просторова музика» та «музична інсталяція»; засоби звукової онтології проаналізовано в безпосередньому зв’язку з онтологіями простору й місця. Висновки. Дослідження виявило, що концепції акустичного простору середини ХX ст., базуючись на бінарних конструкціях чоловіче/жіноче, раціональне/ірраціональне та західне/незахідне, з метою формулювання ідеї акустичного простору як чуттєвого й хаотичного, що виникло для сприйняття раціонального та впорядкування візуального простору, репрезентували великий проект в межах західної музичної композиції: відродження раціонального, логічного та об’єктивного стосовно звучання. Використання звуку як основного медіа сприяє розкриттю унікальних можливостей мистецтва інсталяції, органічно поєднуючи властивості простору й місця з характеристиками звуку та специфікою сприйняття людною різноманітних його атрибутів, пропонуючи новаторський взаємозв'язок акустичного простору 3 його історичними, соціальними, наративними, тактильними й фізичними аспектами.

Ключові слова: звукова інсталяція; простір; місце; звук; звукопередача; «просторовий звук»
\end{abstract}

\title{
Вступ
}

Наприкінці XX - на початку XXI ст. активізуються дослідження різноманітних аспектів звукового мистецтва, проте проблематика звукової інсталяції, через ії̈ граничне положення на межі музики та образотворчого мистецтва, не отримала відповідного наукового осмислення. Результатом цього є разюча невідповідність між академічним розумінням мистецтва звукової інсталяції та його масштабною популяризацією в сучасному соціомистецькому просторі. Серед представлених у сучасному вітчизняному та зарубіжному науковому вимірі праць, проблематика яких корелює $з$ темою даної статті, назвемо дослідження Р. Мінарда «Мистецтво звукової інсталяції» (1996), Г. Оузонян «Втілений звук: слухова архітектура і тіло» (2006) та «Звукове мистецтво і просторові практики: розміщення мистецтва звукової інсталяції» (2008), В. Пулкі та ін. «Просторовий звук та віртуальна акустика» (2007), Р. Марторана «Просторове уявлення мовчазного джерела звуку» (2017), а також статті О. Ландяк «Медіа-арт в контексті сучасного екранного мистецтва» (2015), К. Станіславської «Звукова інсталяція у просторі вуличного мистецтва» (2017), в яких розглядається проблематика організації звукових об'єктів у фізичні простори, перетворення соціальних просторі за допомогою звуку, використання звуку для розкриття виміру тіла та ін.

Проте окремі наукові публікації українських та зарубіжних учених, присвячені дослідженню теорії та історії звукової інсталяції не висвітлюють усіх аспектів означеного питання.

(C) Волкомор В. В., 2020 


\section{МУЗИЧНЕ МИСТЕЦТВО}

ISSN 2410-1176 (Print) • Вісник КНУКіМ. Серія: Мистецтвознавство. Вип. 43 • ISSN 2616-4183 (Online)

На відміну від багатьох музичних творів, звукові інсталяції організують звуки в просторі, відповідно вони вимагають нових теоретичних та аналітичних моделей, враховуючи просторове розміщення звуку. Аналіз досліджень доводить, що існуючі дискурси про «просторовий звук» надають перевагу технічному опису локалізації звуку. У даному дослідженні концепції простору інтерпретуються в соціокультурному аспекті.

Актуальність дослідження зумовлена необхідністю заповнити лакуну в українському академічному вимірі стосовно мистецтва звукової інсталяції.

Наукова новизна полягає в тому, що як доповнення до розробки альтернативної та критичної історії мистецтва звукової інсталяції, у статті використано міждисциплінарну методологію критичного просторового аналізу та критичних досліджень у музиці для вивчення концепцій простору та місця, що стали основою для практики звукової інсталяції в середині XX - на початку XXI ст. Вперше у вітчизняному мистецтвознавстві сутнісні основи звукової інсталяції виявляються в контексті трактування концепції відображеного звукового об'єкту, альтернативних та розширених концепцій простору, зокрема концепції простору як суспільного виробництва; розглянуто поняття «просторовий звук», «просторова музика» та «музична інсталяція»; засоби звукової онтології проаналізовано в безпосередньому зв'язку з онтологіями простору й місця.

\section{Мета статті}

Визначити особливості розвитку мистецтва звукової інсталяції в контексті концепцій акустичного простору другої половини XX - початку XXI ст.

\section{Виклад матералу дослідження}

Звукові інсталяції - це особливий жанр саунд-арту, в якому поєднано властивості простору, характеристики звуку та особливий модус захопленості глядача, який одночасно є слухачем. Даний мистецький феномен, що в першу чергу пов'язаний з відтворенням та сприйняттям простору і місця, доцільно розглядати в межах галузі «ситуативних звукових практик»- будь-яких музичних або звукових практик, що підкреслюють просторові аспекти звукового досвіду та враховують не лише аспекти штучного середовища, архітектури та соціальних просторів, а й часовий вимір простору, виражений через пам'ять та історію.

У даній статті спираємося на критичну просторову теорію дослідження ідеї про те, що простір та місце є соціальними та культурними продуктами.

До 70-х рр. ХХ ст. термін «простір» використовувався переважно для опису геометричних об'ємів та форм, означених аксіомами евклідової геометрії. Лише в 1974 р. французький філософ А. Лефевр (Lefebvre, 1991, с. 23) у праці «The Production of Space» запропонував власне розуміння поняття просторовості, що включає тіло, дію та сконструйоване середовище, стверджуючи, що простір створюється в межах діалектичних відношень між соціальною дією та просторовим оформленням, відповідно є соціальною конструкцією, а не абсолютним або природним явищем.

На сучасному етапі термін «простір» все частіше відноситься до детериторіальних форм, неспецифічних явищ, а «місце» зазвичай використовують для опису локалізованих, територіальних явищ (Lippard, 1997, c. 7). Вирішальну роль в розробці словника для опису нового досвіду простору і місця, що виникає в сучасних інформаційних культурах, відіграли теоретики і філософи нових медіа - М. Маклюен, П. Леві, П. Віріліо та Д. Харауей, а критичні концепції простору і місця в контексті сучасних мережевих суспільств належать М. Кастальсу та М. Оге (Couldry \& McCarthy, 2004; Levy, 2001). На основі їх наукових праць, можемо визначити, що простір (як багатоманітні, динамічні та гібридні соціокультурні умови виробництва) використовується для опису загальних та сталих форм організації, а місце фокусує приватне, ситуативне і миттєве, тому завжди занаходиться в русі та є змінним. Оскільки простір та місце породжують одне одного, існує постійна взаємодія між приватним і загальним, миттєвим та тривалим.

У даному формулюванні простір та місце розуміються як взаємовигідні-простір може відображуватися в термінах реальних та уявних відстаней.

В 1958 р. найвідоміший теоретик в галузі ЗМІ М. Маклюен висловив припущення про існування двох різноманітних бінарних структур сприйняття, що керують уявленям освічених та неосвічених суспільств. Дослідник означив ці структури як «візуальний простір» та «акустичний простір» (Carpenter 
\& McLuhan, 1972, с. 42), наголошуючи, що коли візуальний простір структурує західну думку - лінійну, впорядковану та визначену, акустичний простір структурує «розум примітивної істоти, відповідно не має сенсу, напряму і горизонту» (McLuhan, 1972, с. 189). Паралельно композитори та звукорежисери, які працювали в межах зародження традицій електроакустичної музики, розробляли нові технології, 3 метою створення в хаотичному акустичному просторі відсутній горизонт, розробивши такі пристрої (наприклад, «рupitred'espace», що дозволяв виконавцю спрямовувати попередньо записаний звук на кілька динаміків під час живого виступу), надаючи звуку перспективу, лінійний порядок та сприяючи ефективній візуалізації акустичного простору.

Есенціалістські та універсальні концепції акустичного простору в просторовій музичній композиції середини XX ст., теорії медіа та архітектурі засновувалися на таких дедуктивних бінарних зв'язках як чоловіче/жіноче, раціональне/ірраціональне та західне/незахідне, щоб сформулювати ідею акустичного простору як чуттєвого і хаотичного, що виникло для сприйняття раціонального та впорядкування візуального простору (Ouzounian, 2008, с. 56). Спираючись на означені бінарні конструкції, тогочасні концепції акустичного простору репрезентували великий проект в межах західної музичної композиції: відродження раціонального, логічного та об'єктивного стосовно звучання.

Можливість створювати «просторову музику» 3'явилася після Другої світової війни, коли магнітна стрічка стала комерційно доступною, оскільки саме вона пропонувала еквівалент між часом та простором в середовищі звуку (музичний час можна було виміряти з точки зору фізичної відстані - довжини стрічки). Композитори прагнули використовувати цю новоявлену пластичність звукових матеріалів, відповідно трансформували власні музичні практики в межах мови та естетики скульптури.

Під час Всесвітньої виставки в Брюселі (1958р.) у павільйоні Філіпс було інстальовано «Електронну поему» - автором концептуальної основи восьмихвилинного мультимедійного видовища був Ле Корбюзьє, який задумав його як «поєднання звуку, світла, кольору та ритму» у формі електронного вірша. Архітектуру павільйону та двохвилинну інтерлюдію «Сoncrète Р. Н» розробив Я. Ксенакіс, а безпосередньо звуковий твір - франко-американський композитор Е. Варезе.

O. Маттіс (Mattis, 1992, с. 558) акцентує, що Е. Варезе розробляв естетику просторової музики з 1930-х рр. - знакова просторова музична композиція, що зазвичай теоретизується як набір звукових геометрій, використовувала концептуальні тропи у власних багатошарових співставленнях акустичного та візуального простору. 3 одного боку, музика втілювала в собі примітивну естетику-чуттєвість і була відображена на «акустичному» терміні акустичної/візуальної двоїстої системи, а з другого - «Електронна поема» прагнула визначити місцеположення «звукових об'єктів» у порожньому евклідовому просторі, що було концептуально виявлено на «візуальному» терміні акустичного/візуального бінарного. Відповідно даний музичний твір було спрямовано на надання акустичному простору якостей, що були пов'язані з простором візуальним: розбірливість, раціональність та визначеність. Іншими словами, проект з «візуалізації», а відповідно і раціоналізації та териториалізації звукових об'єктів було виконано з метою прирівняння музики до рівня інших форм візуальної культури. Е. Варезе прагнув звільнити західну музику від багатьох обмежень: системи з однаковими темпами, обмежених динамічних діапазонів, тональної мови, переваги в розвитку мелодії перед тембральною модуляцією. Він прагнув звільнити музику, щоб вона могла випромінювати «відчуття звукової проекції в просторі»: «насправді в музиці три виміри: горизонтальний, вертикальний та динамічні збільшення і зменшення. Я додам четвертий, звукову проекцію - це відчуття, що звук не лишає нам надії на відображення, відчуття, схоже на те, що викликається променями світла, при випромінюванні сильним прожектором - для вуха, як для ока, це відчуття проекції, мандрівка у космос» (Varèse, 2004, с. 18-19). Відповідно концепції Е. Варезе, просторова музика не пов'язана $з$ дискретними маніпуляціями мелодичного і гармонічного розвитку, а їі повноцінне вираження, що могло б розвинутися як структурне ціле - це логічна, розбірлива система.

В середині XX ст. концепція відображеного звукового об'єкту була прийнята в західних музичних традиціях. Водночас було сформульовано альтернативні та розширені концепції простору. Серед них була ідея простору як суспільного виробництва, яку досліджували художники- та філософи-ситуаціоналісти, зокрема А. Лефевр. Запропонована ними «цілісна художня діяльність майбутнього» пропонувала інструменти для поєднання та інтегрування життя з середовищем в процесі поєднання з «культурою в цілому». В праці «The Production of Space» А. Лефевр (Lefebvre, 1991, с. 2) наголошує, що створенню простору сприяють три процеси: просторові практики (процеси виробництва та відтворення, тобто влада і культура), репрезентації простору (як простір репрезентований в мові) та репрезентативний простір (живе, повсякденне сприйняття простору). Заохочуючи альтернативні простори та форми, він підтримував таємні просторові практики і шукав у мистецтві приклади розширеного просторового уявлення. 


\section{МУЗИЧНЕ МИСТЕЦТВО}

ISSN 2410-1176 (Print) • Вісник КНУКіМ. Серія: Мистецтвознавство. Вип. 43 • ISSN 2616-4183 (Online)

Г. Узунян (Ouzounian, 2008, с. 282) стверджує, що витоки звукової інсталяції полягають не в якомусь одному творі або митці, а в мережі ідей та практик, що змогли вивести просторове уявлення на перший план західного мистецтва і музики в середині XX ст.

Появу наприкінці 1960-х рр. терміну «мистецтво звукової інсталяції» в сучасних дискурсах звукового мистецтва приписують американському перкусіоністу, звукорежисеру М. Нойхаусу, який визначає його як твори, в яких «немає початку і кінця», а звуки «поміщені в простір, а не у час» (Ouzounian, 2006, c. 73). За М. Нойхаусом звукові інсталяції позиціонувалися як вид мистецтва, що може перетинатися 3 повсякденним життям публіки та змінювати їх ставлення до буденних просторів, в яких вони проживають. В 1967 р. він створює першу звукову інсталяцію «Drive-InMusic» - установку було розміщено у звичному просторі (узбіччі дороги на Буффало), а слухачі чули комбінації синусоїдальних тонів, що несподівано відтворювалися їх автомобільними радіоприймачами та залежали від таких умов навколишнього середовища як вологість та світло.

Натомість сучасні дослідники визначають звукові інсталяції як «просторово-організовані звукові твори», що включають широкий набір практик, варіюючися від просторової музичної композиції до скульптури звукового перформансу» (Ouzounian, 2008, с. 283).

На думку звукорежисера і теоретика мистецтва звукозапису Р. Мінара (Minard, 1996), звукові інсталяції - це роботи, що «артикулюють» та «зумовлюють» простір, відповідно доцільно розглядати їх як частину категорії інсталяційного мистецтва: «в звуковій інсталяції ми знаходимо цю особливу якість взаємовідносин, що виражається між аудіо, відео та/або архітектурними елементами, для яких задумано твір, а також між звуком, простором і спостерігачем» (с. 9).

Локалізація звуку заснована на акустичних і не акустичних сигналах, що інтегровані в мозок, з метою отримання більш точного просторового уявлення слухової сцени. В деяких випадках фізичні об'єкти сприймаються слухачем як потенційні джерела звуку (Martorana, 2017, с. 1).

Позиціонуємо звукову інсталяцію як просторово організований звуковий твір, що надає перевагу концепціям та досвіду простору і місця; може бути статичними або мобільними, включати елементи виконання, запису або трансляції; може репрезентуватися в кількох просторах і часах (реальних, віртуальних та уявних), відбуватися в галереях, музеях, електронних мережах та різноманітних нетрадиційних місцях.

Дослідники стверджують, що серйозний економічний бар'єр до 80-х рр. XX ст. не сприяв розвитку звукових інсталяцій та саунд-арту в цілому (Лукьянова, 2015, с. 78), оскільки звукооброблююча та звуковідтворююча техніка була досить дорогою і лише масове поширення персональних комп'ютерів та MIDI - цифрового інтерфейсу музичних інструментів - дозволило художникам розпочати активний розвиток різноманітних форм мистецтва звуку, спровокувавши хвилю різноманітних саунд-практик (Schedel \& Uroskie, 2001, c. 4).

3 кінця 1960-х рр. американський композитор М. Амахер створює звукові інсталяції для конкретних місць, що виробляють різноманітні психоакустичній ефекти. В 1999 р. вона випустила компакт-диск із записом деяких інсталяцій, акцентуючи, що слухати їх потрібно лише через динаміки, а не навушники (це пов'язано зі специфікою психоакустичних ефектів, які можуть бути досягнуті лише за умови розвитку звуків у фізичних архітектурних просторах).

Натомість австрійський архітектор і художник звукової інсталяції Б. Лейтнер у 2003 р. випустив компакт-диск «KÖPFRAUME», призначений для прослуховування через навушники, а не через динаміки, оскільки звукові композиції вміщують «тривимірні звукові скульптури», що утворюються у внутрішньому просторі слухача.

Початок XXI ст. ознаменувався активізацією виставок звукового мистецтва, серед яких назвемо «Мистецтво звуку» (Лондон, Галерея Хейворд, 27 квітня -18 червня 2000 p.), «Sonic Process: Нова географія звуку» (Париж, Центр Жоржа Помпіду, 16 жовтня 2002 р. - 6 січня 2003 р.), «Сини Люм’єрів: Історія звуку в мистецтві XX століття» (Париж, Центр Жоржа Помпіду, 22 вересня 2004 р. - 3 січня 2005 p.), «Soundings: A Contemporary Score» (Нью-Йорк, МоМА, 10 серпня - 3 листопада 2013 р.), «Ореn Museum. Open City» (Рим, MAXXI, 24 жовтня - 30 листопада 2014 р.) та ін., а також зростанням кількості фестивалів звукового мистецтва, наприклад, австралійський «Liquid Arts», американські «Sonic Circuits» та «Outer Ear», німецькі «Klang-Kunst Festival», канадський «Sound Travels», японський «Xebec Sound Arts» та ін.

На сучасному етапі аудіо технології досягли високого рівня розвитку, відповідно багато монофонічних характеристик звуку, зокрема частотний спектр та часова структура можуть відтворюватися за допомогою сучасних мікрофонів та гучномовців з такою якістю, що слухач не зможе вловити різницю між оригіналом та відтворенням. 


\section{Висновки}

Дослідження виявило, що концепції акустичного простору середини XX ст., грунтуючись на бінарні конструкції чоловіче/жіноче, раціональне/ірраціональне та західне/незахідне, з метою формулювання ідеї акустичного простору як чуттєвого і хаотичного, що виникло для сприйняття раціонального та впорядкування візуального простору, репрезентували великий проєкт в межах західної музичної композиції: відродження раціонального, логічного та об'єктивного стосовно звучання. Використання звуку як основного медіа сприяє розкриттю унікальних можливостей мистецтва інсталяції, органічно поєднуючи властивості простору та місця 3 характеристиками звуку та специфікою сприйняття людною різноманітних його атрибутів, пропонуючи новаторський взаємозв'язок акустичного простору 3 його історичними, соціальними, наративними, тактильними та фізичними аспектами. Внаслідок аналізу протиріччя між простором і місцем, що сформульовані в просторово-організованих звукових творах виявлено, що мистецтво звукової інсталяції протягом історії розвитку рухається у напрямку від «простору» до «місця», або від абсолютного та універсального до раптового і приватного.

Перспективи подальших досліджень полягають в осмисленні інноваційних звукових технологій просторової звукопередачі, що використовуються в процесі оформлення аудіовізуальних інсталяцій. На нашу думку, це дозволяє виявити специфіку їх застосування на сучасному етапі відповідно особливостям внутрішніх та зовнішніх просторів, а також надати уявлення про деякі тенденції розвитку мистецтва звукової інсталяції в ретроспективі.

\section{Список використаних джерел}

Лукьянова, О. Я. (2015). К проблеме феноменологии звука. Артикульт, 18(2), 77-85. http://articult.rsuh.ru/articult18-2-2015/o-y-lukyanova-to-the-problem-of-the-phenomenology-of-sound.php.

Carpenter, E., \& McLuhan, M. (1972). Acoustic Space. In E. Carpenter \& M. McLuhan (Eds.), Explorations in Comminucation: An Anthology (pp. 65-70). Beacon Press.

Couldry, N., \& McCarthy, A. (Eds.). (2004). Mediaspace: Place, Scale, and Culture in a Media Age. Routledge.

Lefebvre, H. (1991). The Production of Space (D. Nicholson-Smith, Trans.). Blackwell.

Levy, P. (2001). Cyberculture (R. Bononno, Trans.). University of Minnesota Press.

Lippard, L. R. (1997). The Lure of the Local: Senses of Place in a Multicentered Society. New Press.

Martorana, R. (2017). Spatial Representation of a Silent Sound Source. Sound and space 2016/2017. Institute of Sonology, Royal Conservatoire, Hague. https://www.researchgate.net/publication/332060570_Spatial_Representation of_a Silent_Sound_Source.

Mattis, O. (1992). Varèse's Multimedia Conception of Deserts. The Musical Quarterly, 76(4), 557-583. https://doi. org/10.1093/mq/76.4.557.

McLuhan, M. (1972). Five Sovereign Fingers Taxed the Breath. In E. Carpenter \& M. McLuhan (Eds.), Explorations in Comminucation: An Anthology (pp. 207-208). Beacon Press.

Minard, R. (1996). Sound Installation Art. Institut für Elektronische Musik (IEM) an der Hochschulefür Musik und darstellen de Kunst.

Ouzounian, G. (2006). Embodied Sound: Aural Architecture and the Body. Contemporary Music Review, 25(1/2), 69-79.

Ouzounian, G. (2008). Sound Art and Spatial Practices: Situating Sound Installation Art Since 1958 (PhD Dissertation). University of California, San Diego.

Pulkki, V., Faller, C., Härmä, A., Lokki, T., \& Bruijn, W. de. (2007). Spatial Sound and Virtual Acoustics. EURASIP Journal on Advances in Signal Processing, 2007, Article 072647. https://doi.org/10.1155/2007/72647.

Schedel, M., \& Uroskie, A. V. (2011). Introduction: Sonic Art and Audio Cultures: Writing about Audiovisual Culture. Journal of Visual Culture, 10(2), 1-8. https://doi.org/10.1177/1470412911402879.

Varèse, E. (2004). The Liberation of Sound. In C. Cox \& D. Warner (Eds.), Audio Culture: Readings in Modern Music (pp. 17-21). Continuum.

\section{References}

Carpenter, E., \& McLuhan, M. (1972). Acoustic Space. In E. Carpenter \& M. McLuhan (Eds.), Explorations in Comminucation: An Anthology (pp. 65-70). Beacon Press [in English].

Couldry, N., \& McCarthy, A. (Eds.). (2004). Mediaspace: Place, Scale, and Culture in a Media Age. Routledge [in English]. 


\section{МУЗИЧНЕ МИСТЕЦТВО}

ISSN 2410-1176 (Print) • Вісник КНУКіМ. Серія: Мистецтвознавство. Вип. 43 • ISSN 2616-4183 (Online)

Lefebvre, H. (1991). The Production of Space (D. Nicholson-Smith, Trans.). Blackwell [in English].

Levy, P. (2001). Cyberculture (R. Bononno, Trans.). University of Minnesota Press [in English].

Lippard, L. R. (1997). The Lure of the Local: Senses of Place in a Multicentered Society. New Press [in English].

Lukianova, O. Ya. (2015). K probleme fenomenologii zvuka [Towards a Phenomenology of Sound]. Artikult, 18(2), 77-85. http://articult.rsuh.ru/articult-18-2-2015/o-y-lukyanova-to-the-problem-of-the-phenomenology-of-sound.php [in Russian].

Martorana, R. (2017). Spatial Representation of a Silent Sound Source. Sound and space 2016/2017. Institute of Sonology, Royal Conservatoire, Hague. https://www.researchgate.net/publication/332060570_Spatial_Representation_of_a Silent_Sound_Source [in English].

Mattis, O. (1992). Varèse's Multimedia Conception of Deserts. The Musical Quarterly, 76(4), 557-583. https://doi. org $/ 10.1093 / \mathrm{mq} / 76.4 .557$ [in English].

McLuhan, M. (1972). Five Sovereign Fingers Taxed the Breath. In E. Carpenter \& M. McLuhan (Eds.), Explorations in Comminucation: An Anthology (pp. 207-208). Beacon Press [in English].

Minard, R. (1996). Sound Installation Art. Institut für Elektronische Musik (IEM) an der Hochschulefür Musik und darstellen de Kunst [in English].

Ouzounian, G. (2006). Embodied Sound: Aural Architecture and the Body. Contemporary Music Review, 25(1/2), 69-79 [in English].

Ouzounian, G. (2008). Sound Art and Spatial Practices: Situating Sound Installation Art Since 1958 (PhD Dissertation). University of California, San Diego [in English].

Pulkki, V., Faller, C., Härmä, A., Lokki, T., \& Bruijn, W. de. (2007). Spatial Sound and Virtual Acoustics. EURASIP Journal on Advances in Signal Processing, 2007, Article 072647. https://doi.org/10.1155/2007/72647 [in English].

Schedel, M., \& Uroskie, A. V. (2011). Introduction: Sonic Art and Audio Cultures: Writing about Audiovisual Culture. Journal of Visual Culture, 10(2), 1-8. https://doi.org/10.1177/1470412911402879 [in English].

Varèse, E. (2004). The Liberation of Sound. In C. Cox \& D. Warner (Eds.), Audio Culture: Readings in Modern Music (pp. 17-21). Continuum [in English].

Стаття надійшла до редакиії: 29.09.2020

\section{ИННОВАЦИОННЫЕ ЗВУКОВЫЕ \\ ТЕХНОЛОГИИ ПРОСТРАНСТВЕННОЙ Преподаватель, \\ ЗВУКОПЕРЕДАЧИ: РЕТРОСПЕКТИВА Киевский национальный университет ЗВУКОВЫХ ИНСТАЛЛЯЦИЙ культуры и искусств, \\ Киев, Украина}

Цель статьи - определить особенности развития искусства звуковой инсталляции в контексте концепций акустического пространства второй половины XX в. - начала XXI века. Методы исследования. Применена междисциплинарная методология критического пространственного анализа и критических исследований в музыке для изучения концепций пространства и места, ставшие основой для практики звуковой инсталляции в середине XX - начала XXI в.; системный и эволюционный методы, которые поспособствовали рассмотрению музыкальной инсталляции в общей философско-онтологической плоскости с целью получения результатов, полезных в музыкальных и смежных науках. Научная новизна. Исследованы особенности формирования и развития искусства звуковой инсталляции сквозь призму концепций акустического пространства второй половины XX - начала XXI в.; впервые в отечественном искусствоведении сущностные основы звуковой инсталляции оказываются в контексте трактовки концепции отраженного звукового объекта, альтернативных и расширенных концепций пространства, в частности концепции пространства как общественного производства; рассмотрено понятие «пространственный звук», «пространственная музыка» и «музыкальная инсталляция»; средства звуковой онтологии проанализированы в непосредственной связи с онтологиями пространства и места. Выводы. Исследование показало, что концепции акустического пространства середины XX в., основываясь на бинарных конструкциях мужское / женское, рациональное / иррациональное и западное / незападное, с целью формулирования идеи акустического пространства как чувственного и хаотичного, возникшего для восприятия рационального и упорядочения визуального пространства, представляли большой проект в пределах западной музыкальной композиции: возрождение рационального, логического и объективного относительно звучания. Использование звука в качестве основного медиа способствует 
раскрытию уникальных возможностей искусства инсталляции, органично сочетая свойства пространства и места с характеристиками звука и спецификой восприятия человеком различных его атрибутов, предлагая новаторскую взаимосвязь акустического пространства с его историческими, социальными, нарративными, тактильными и физическими качествами.

Ключевые слова: звуковая инсталляция; пространство; место; звук; звукопередача; «пространственный звук»

\author{
INNOVATIVE SOUND TECHNOLOGIES Vitalii Volkomor \\ OF SPATIAL SOUND TRANSMISSION: Lecturer, \\ A RETROSPECTIVE OF SOUND Kyiv National University of Culture and Arts, \\ INSTALLATIONS Kyiv, Ukraine
}

The purpose of the article is to determine the peculiarities of the development of the art of sound installation in the context of the concepts of acoustic space in the second half of the 20th - beginning of the 21st century. Research Methodology. The interdisciplinary methodology of critical spatial analysis and critical research in music has been applied to study the concepts of space and place, which became the basis for the practice of sound installation in the middle of the 20th century and the beginning of the $21 \mathrm{st}$; systemic and evolutionary methods that have contributed to the consideration of the musical installation in the general philosophical and ontological plane in order to obtain the results useful in music and related sciences. Scientific Novelty. The peculiarities of the formation and development of the art of sound installation through the prism of the concepts of acoustic space of the second half of the 20th - beginning of the 21st century have been studied; for the first time in Ukrainian art studies, the essential foundations of sound installation are revealed in the context of the interpretation of the concept of a reflected sound object, alternative and extended concepts of space, in particular, the concept of space as a social production; the concepts of "spatial sound", "spatial music" and "musical installation" have been considered; the means of sound ontology have been analysed in direct connection with the ontologies of space and place. Conclusions. The study has revealed that the concepts of acoustic space of the middle of the 20th century, based on the binary constructions male/female, rational/ irrational and Western/non-Western, in order to formulate the idea of acoustic space as sensual and chaotic, which arose for the perception of rational and ordering of visual space, represented a large project within the Western musical composition: the revival of rational, logical and objective as to the sounding. The use of sound as the main media contributes to the disclosure of the unique possibilities of the art of installation, organically combining the properties of space and place with the characteristics of sound and the specificity of human perception of its various attributes, offering an innovative relationship of acoustic space with its historical, social, narrative, tactile and physical qualities.

Keywords: sound installation; space; place; sound; sound transmission; "spatial sound" 